\title{
Preparation and biological activity evaluation of some benzoylthiourea and benzoylurea compounds
}

\author{
Antar A. Abdelhamid ${ }^{a}$, A. M. M. Elsaghier ${ }^{a}$, Safwat A. Aref ${ }^{b}$, Mohamed A. Gad ${ }^{*}$, N. A. Ahmed ${ }^{b}$ and $^{\text {Aham }}$ \\ Shaban A. A. Abdel-Raheem ${ }^{c}$
}

${ }^{a}$ Department of Chemistry, Faculty of Science, Sohag University, 8252, Sohag, Egypt

${ }^{b}$ Research Institute of Plant Protection, Agricultural Research Center, 12112 Giza, Egypt

${ }^{c}$ Soil, Water, and Environment Research Institute, Agriculture Research Center, Giza, Egypt

\section{H R O N I C L E}

Article history:

Received March 20, 2021

Received in revised form May 12, 2021

Accepted June 17, 2021

Available online

June 17, 2021

Keywords:

Synthesis

Benzoylthiourea and Benzoylurea

Insect Growth Regulators

Evaluation \begin{abstract}
A B S T R A C T
Due to the complicated problems coming from excessive applications of insecticides, searching for safe substitutes to these insecticides has become a necessity. Thus, the insect growth regulators are candidates to be used in such concern. Comparative studies of the effects of three compounds, 2-benzoyl- $N$-phenylhydrazine-1-carbothioamide (1), 2-(cyanoacetyl)- $N$ phenylhydrazine-1-carboxamide (2) and $N$-(2-(2-cyanoacetyl)hydrazinecarbonothioyl)furan-2carboxamide (3) (an insect growth regulator inhibiting chitin synthesis), were conducted on Spodoptera littoralis (Boisduval, 1833). The compounds, orally administered, caused larval mortality proportional to the concentrations in the food source. larvae were unable to complete the molting process and died in the old larval cuticle. Larvae contaminated by sublethal doses completed their development to adulthood. $N$-(2-(2-cyanoacetyl)hydrazinecarbonothioyl)furan2-carboxamide (3) is more active than the other compounds have $\mathrm{LC}_{50} 17.082 \mathrm{ppm}$ for $2^{\text {nd }}$ instar larvae and $60.832 \mathrm{ppm}$ for $4^{\text {th }}$ instar larvae.
\end{abstract}

\section{Introduction}

Organic compounds are very important in nature due to their different applications. ${ }^{1-17}$ Urea and Thiourea its derivatives constitute an important class of heterocyclic compounds which possess wide range therapeutic and pharmacological properties. Sulphonylureas become widely available in 1955 for the treatment of non-ketosis mild diabetes and are still being the drugs of choice. ${ }^{18}$ Benzoylurea and benzoylthiourea insecticides have many attractive properties such as high selectivity, ${ }^{19}$ high biological activity, rapid degradation in soil and water and the acute low toxicity for animals, which make them suitable for inclusion in integrated pest management programs for crops. ${ }^{20}$ On the other hand, many Urea and Thiourea compounds have been developed into insecticide, fungicides, insecticides and other agricultural chemicals. ${ }^{21}$ IGRs include juvenile hormone $(\mathrm{JH})$, mimic and chitin synthesis inhibitors (CSIs). ${ }^{22}$ CSIs, such as hexaflumuron, lufenuron and diflubenzuron, which inhibit the production of chitin, a major component of the insect exoskeleton. Insects treated with CSIs become unable to synthesize new cuticle, and therefore unable to successfully molt into the next stage. ${ }^{23}$ CSIs

* Corresponding author.

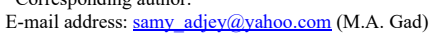

(C) 2021 by the authors; licensee Growing Science, Canada

doi: $10.5267 /$ j.ccl.2021.006.001 
may be toxic to other arthropods, and IGR metabolites may have adverse effects on vertebrates due to their ability to bind to certain members of the nuclear hormone receptor family. ${ }^{24}$ The benzoylurea constitute a class of the IGRs that interfere with insect growth and development by inhibiting chitin synthesis in insects. ${ }^{25}$ The cotton leafworm Spodoptera littoralis (Boisd.) is a major polyphagous key pest in Egypt. It has been well established that diflubenzuron (DFB) inhibits chitin synthesis in vivo and that such action constitutes the main insecticidal mechanism of this compound. However, the precise molecular mechanism of its action has not been elucidated. ${ }^{26}$

\section{Results and Discussion}

\subsection{Chemistry}

Following our project in preparation and toxicity evaluation of juvenile hormones analogues, here we prepared three compounds that are shown in Fig. 1. The three compounds, namely, 2-benzoyl- $N$ phenylhydrazine-1-carbothioamide 1, 2-(cyanoacetyl)- $N$-phenylhydrazine-1-carboxamide 2 and $N$-(2(2-cyanoacetyl)hydrazinecarbonothioyl)furan-2-carboxamide $\mathbf{3}$ were prepared as follow:

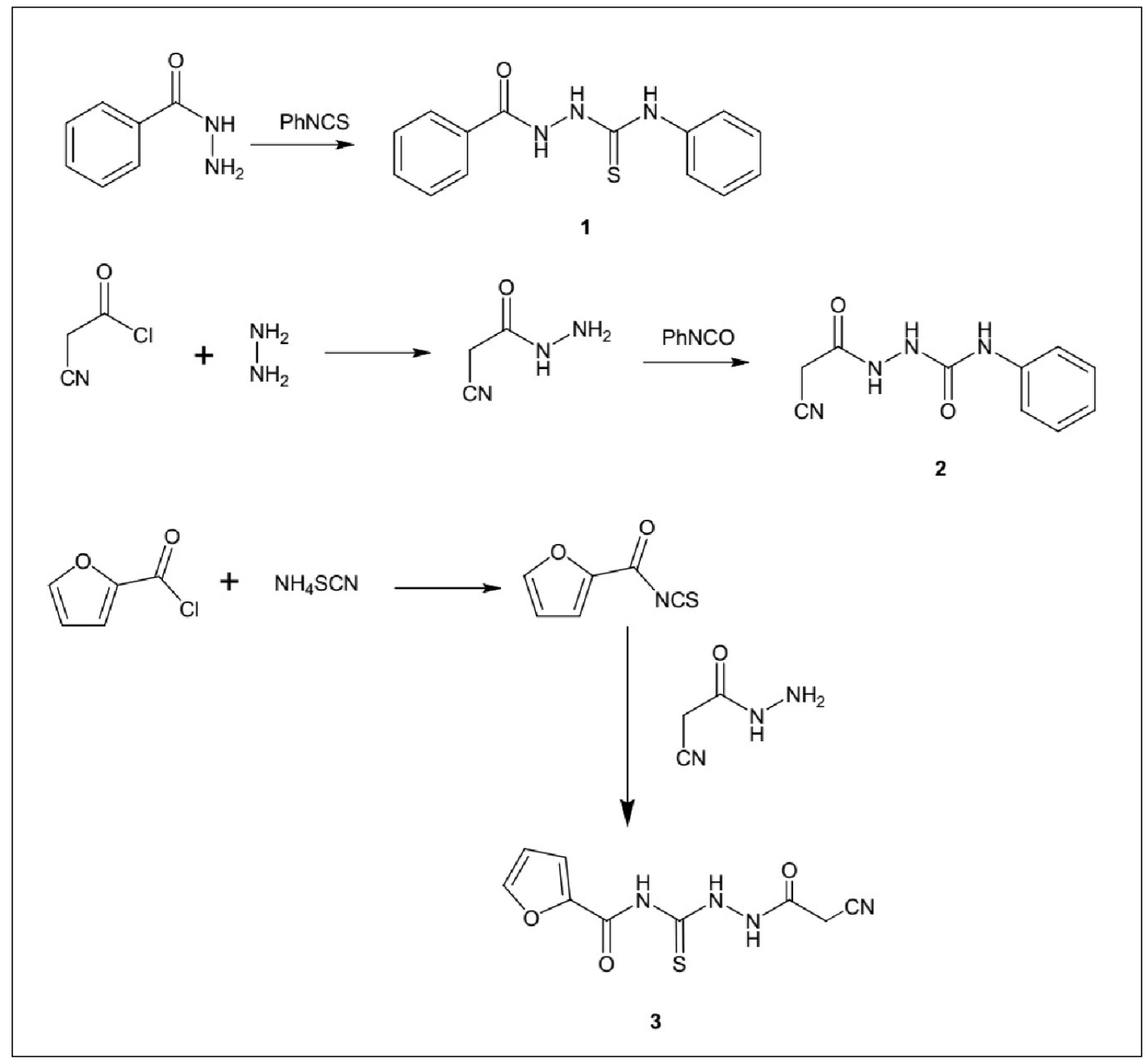

Fig. 1. Synthesis of compounds 1, 2 and 3.

Compounds 1 and 2 were prepared according to the reported methods. ${ }^{27,28}$ In addition to the procedure reported before, ${ }^{29}$ compound $\mathbf{3}$ was synthesized here by reaction of furan-2-carbonyl chloride with ammonium thiocyanate that gave furan-2-carbonyl isothiocyanate which reacted with 2- 
cyanoacetohydrazide to give compound 3. Spectroscopic data and elemental analyses of compound $\mathbf{3}$ were in agreement with its proposed structure.

\subsection{Insecticidal activity of compounds 1,2 , and 3 .}

The objective tested compounds have been used for insecticidal activity as explained beneath:

As shown in Table 1, target compounds were tested of their activity as insecticides in which shown beneath. Three previously mentioned compounds displayed strong to weak toxic action against the $2^{\text {nd }}$ instar larvae in light of the fact that various of them were active after $72 \mathrm{hr}$. of the test LC50 values of compounds 1, 2 and $\mathbf{3}$ were 73.125, 26.635 and 17.082 ppm, respectively.

As shown in Table 1, target compounds were tested for their activity as insecticides and this is shown beneath. three previously mentioned compounds displayed strong to weak toxic action against the $4^{\text {th }}$ instar larvae after $72 \mathrm{hrs}$ of the treatment in which LC 50 values changed from 103.125 to 145.908 ppm for compounds 1 and 2 while compound 3 LC 50 was 60.832 ppm.

Table 1. Insecticidal activity of compounds 1-3 against the larvae of Spodoptera Littoralis (Boisd.), after $72 \mathrm{~h}$ of treatments.

$2^{\text {nd }}$ instar larvae $\quad 4^{\text {th }}$ instar larvae

\begin{tabular}{ccccccc}
\hline Compd & $\begin{array}{c}\text { LC } \\
(\mathbf{p p m})\end{array}$ & slope & $\begin{array}{c}\text { Toxic } \\
\text { ratio }\end{array}$ & $\begin{array}{c}\text { LC50 } \\
(\mathbf{p p m})\end{array}$ & slope & Toxic ratio \\
\hline $\mathbf{1}$ & 73.125 & $0.246 \pm 0.0805$ & 0.233 & 103.125 & $0.234 \pm 0.0830$ & 0.580 \\
$\mathbf{2}$ & 26.635 & $0.246 \pm 0.0805$ & 0.643 & 145.908 & $0.307 \pm 0.0993$ & 0.416 \\
$\mathbf{3}$ & 17.082 & $0.246 \pm 0.0791$ & 1 & 60.832 & $0.225 \pm 0.0820$ & 1 \\
\hline
\end{tabular}

\section{Conclusion}

A chain of benzoylthiourea and benzoylurea which are analogues to insect growth regulators in which contain cyano group were chemically synthesized. The toxic activity of the tested target compounds was assessed against $2^{\text {nd }}$ and $4^{\text {th }}$ instar larvae demonstrated that some of the synthesized target compounds have great toxicological activity, though some of them uncovered sensible aphicidal activity. Particularly, compound $\mathbf{3}$ was the most toxic action since it surpassed the aphicidal activity of a refrance insect growth regulators. The activity concerning compound $\mathbf{3}$ might be because of the presence of the cyano and fuoryl group joined to the atomic structure.

\section{Experimental}

\subsection{Materials and methods}

All melting points are uncorrected and were determined by Kofeler melting point apparatus. IR ( $\mathrm{cm}^{-}$ $\left.{ }^{1}\right)$ spectra were recorded (KBr disc) on a Shimadzu DR-8001 spectrophotometer. ${ }^{1} \mathrm{HNMR}$ (DMSO-d6) spectra were recorded at $200 \mathrm{MHz}$ on a Varian Gemini NMR spectrometer and also at $400 \mathrm{MHz}$, the chemical shift is expressed in $\delta$ value (ppm) using TMS as an internal reference. All NH groups were subjected to hydrogen/deuterium exchange test. Elemental analyses were carried out on a Perkin-Elmer $240^{\circ} \mathrm{C}$ Micro analyzer. The mass spectra were performed on Micro mass $7070 \mathrm{E}$ spectrometer using Direct Inlet and Shimadzu Qp-2010. 
4.2 Synthetic procedure for 2-benzoyl-N-phenylhydrazine-1-carbothioamide (1).

This compound was prepared according to the reported method. ${ }^{27}$

4.3 Synthetic procedure for 2-(cyanoacetyl)-N-phenylhydrazine-1-carboxamide (2).

This compound was prepared according to the reported method. ${ }^{28}$

\subsection{Synthetic procedure for N-(2-(2-cyanoacetyl)hydrazinecarbonothioyl)furan-2-carboxamide (3).}

Mixture of furan-2-carbonyl chloride $(1 \mathrm{~mol})$ with ammonium thiocyanate $(1 \mathrm{~mol})$ refluxed in acetone for $30 \mathrm{~min}$ to give furan-2-carbonyl isothiocyanate. In the same mixture, 2cyanoacetohydrazide was added. The precipitate is recrystallized by absolute ethanol to give white powder of compound 3. Yield: 83\%; MP: $184-186^{\circ} \mathrm{C}$. IR (v) $(\mathrm{KBr}) \mathrm{cm}^{-1}: 3216(3 \mathrm{NH}), 3050,3057(\mathrm{C}-$ HAromatic), 2922, 2827 (C-H aliphatic), 2203(CN), 1664 (CO). ${ }^{1} \mathrm{HNMR}$ (DMSO-d6): $\delta 12.26$ (s, 1H, NH), $11.50(\mathrm{~s}, 1 \mathrm{H}, \mathrm{NH}), 11.15(\mathrm{~s}, 1 \mathrm{H}, \mathrm{NH}), 6.75-8.6\left(\mathrm{~m}, 3 \mathrm{H}\right.$ Ar-H), 3.85 (s, 2H, CH). ${ }^{13} \mathrm{C}$ NMR (DMSO-d $)$ : $\delta 187.53,160.39,157.64,148.75,145.11,119.22,115.52,113.07,24.18$. Elemental analysis calculated for $\mathrm{C}_{9} \mathrm{H}_{8} \mathrm{~N}_{4} \mathrm{O}_{3} \mathrm{~S}$ (\%) Calcd. /found; C: 42.85/42.83, H: 3.60/3.63, N: 24.99/24.97, S: 12.71/12.70.

\subsection{Laboratory bioassay}

The method that measures toxicity of the target compounds was tested by leaf dipping bioassay. Results of research facility screening to discover the suitable concentrations of the objective target compounds which are deformation in the insect to kill half $50 \%$ LC50 of instar larvae were proclaimed here. Five concentrations of arrangement of each synthesized compound in addition to $0.1 \%$ Triton X100 as a surfactant were used. The number of ten 2 nd instar larvae and 4th instar larvae of insects, nearly have the same size, plates $(9 \mathrm{~cm}$. distance across) of castor bean leaves in which dunked in the objective treatment concentrations for $10 \mathrm{~s}$ then left to dry and offered to larvae, which starved for 46 treatment was reproduced multiple times (10 larvae for each). Control was dunked in distilled water only. The larvae were permitted to benefit from treated plates for $48 \mathrm{~h}$., then transferred to the untreated ones. Mortality percentages were recorded after $72 \mathrm{~h}$. for all insecticides. Mortality was redressed by Abbott's formula. ${ }^{30}$ The doses mortality relapse lines were statistically investigated by probit analysis. ${ }^{31}$ Toxicity Index and Relative Potency determined by Sun equations. ${ }^{32}$ Slope esteems and middle deadly focused concentrations LC50 of the title target compounds were determined through a Probit relapse investigation program and recorded in ( $\mathrm{ppm})$. Were inundated for $10 \mathrm{~s}$ in each concentration multiple times (3 times). Pests which were treated were left to dry at room temperature for about half hour. Control clumps of utilized pests were likewise used. The insecticidal action trial of each compound was rehashed multiple times ( 2 times) and the obtained data were rectified by Abbott's equation. By utilizing a modernized probit relapse investigation program, middle deadly fixations ( $\left.\mathrm{LC}_{50}\right)$ and incline estimations of objective target compounds were figured and revealed as (ppm).

\section{References}

(1) Bakhite E. A., Abd-Ella A. A., El-Sayed M. E. A., and Abdel-Raheem Sh. A. A. (2014) Pyridine derivatives as insecticides. Part 1: Synthesis and toxicity of some pyridine derivatives against Cowpea Aphid, Aphis craccivora Koch (Homoptera: Aphididae). J. Agric. Food Chem., 62 (41) 9982-9986.

(2) Nirwan N., Pareek Ch., and Swami V. K. (2020) Indolylimidazoles: Synthetic approaches and biological activities. Curr. Chem. Lett., 9 (2020) 31-50.

(3) Bakhite E. A., Abd-Ella A. A., El-Sayed M. E. A., and Abdel-Raheem Sh. A. A. (2017) Pyridine derivatives as insecticides. Part 2: Synthesis of some piperidinium and morpholinium cyanopyridinethiolates and their Insecticidal Activity. J. Saud. Chem. Soc., 21 (1) 95-104.

(4) Kamal El-Dean A. M., Abd-Ella A. A., Hassanien R., El-Sayed M. E. A., Zaki R. M., and AbdelRaheem Sh. A. A. (2019) Chemical design and toxicity evaluation of new 
pyrimidothienotetrahydroisoquinolines as potential insecticidal agents. Toxicol. Rep., 6 (2019) 100104.

(5) Saddik A. A., Kamal El-Dean A. M., El-Said W. A., Hassan K. M., and Abbady M. S. (2018) Synthesis, Antimicrobial, and Anticancer Activities of a New Series of Thieno[2,3-d] Pyrimidine Derivatives. J. Heterocyclic Chem., 55 (9) 2111-2122.

(6) Saddik A. A., Kamal El-Dean A. M., El-Sokary G. H., Hassan K. M., Abbady M. S., Ismail I. A., and Saber S. H. (2017) Synthesis and Cytotoxicity of Some Thieno[2,3-d]pyrimidine Derivatives. $J$. Chin. Chem. Soc., 64 (1) 87-93.

(7) Kamal El-Dean A. M., Abd-Ella A. A., Hassanien R., El-Sayed M. E. A., and Abdel-Raheem Sh. A. A. (2019) Design, Synthesis, Characterization, and Insecticidal Bioefficacy Screening of Some New Pyridine Derivatives. ACS Omega, 4 (5) 8406-8412.

(8) Abdel-Raheem Sh. A. A., Kamal El-Dean A. M., Zaki R. M., Hassanien R., El-Sayed M. E. A., Sayed M., and Abd-Ella A. A. (2021) Synthesis and toxicological studies on distyryl-substituted heterocyclic insecticides. Eur. Chem. Bull., 10 (4) 225-229.

(9) Tolba M. S., Sayed M., Abdel-Raheem Sh. A. A., Gaber T. A., Kamal El-Dean A. M., and Ahmed M. (2021) Synthesis and spectral characterization of some new thiazolopyrimidine derivatives. Curr. Chem. Lett., Accepted Manuscript (DOI: 10.5267/j.ccl.2021.4.004).

(10) Abdel-Raheem Sh. A. A., Kamal El-Dean A. M., Hassanien R., El-Sayed M. E. A., and Abd-Ella A. A. (2021) Synthesis and characterization of some distyryl-derivatives for agricultural uses. Eur. Chem. Bull., 10 (1) 35-38.

(11) Abdel-Raheem Sh. A. A., Kamal El-Dean A. M., Hassanien R., El-Sayed M. E. A., and Abd-Ella A. A. (2020) Synthesis and biological activity of 2-((3-Cyano-4,6-distyrylpyridin-2yl)thio)acetamide and its cyclized form. Alger. j. biosciences, 01 (02) 046-050.

(12) Lingappa M., Guruswamy V., and Bantal V. (2021) Synthesis and characterization of 4-amino4H-1,2,4-triazole derivatives: Anticonvulsant activity. Curr. Chem. Lett., 9 (2021) 33-42.

(13) Al-Taifi E. A., Abdel-Raheem Sh. A. A., and Bakhite E. A. (2016) Some reactions of 3-cyano-4(p-methoxyphenyl)-5-oxo-5,6,7,8-tetrahydroquinoline-2(1H)-thione; Synthesis of new tetrahydroquinolines and tetrahydrothieno[2,3-b]quinolines. Assiut University Journal of Chemistry (AUJC), 45 (1) 24-32.

(14) Abdel-Raheem Sh. A. A., Kamal El-Dean A. M., Hassanien R., El-Sayed M. E. A., Sayed M., and Abd-Ella A. A. (2021) Synthesis and spectral characterization of selective pyridine compounds as bioactive agents. Curr. Chem. Lett., 10 (2021) 255-260.

(15) Chavan P., Pansare D., Shelke R., Shejul S., and Bhoir P. (2021) Ultrasound-assisted synthesis and biological significance of substituted $4 \mathrm{H}$-chromene-3- carbonitrile using greenery approaches. Curr. Chem. Lett., 10 (2021) 43-52.

(16) Saddik A. A., Hassan K. M., Kamal El-Dean A. M., and Abbady M. S. (2015) Synthesis of new mercaptopyrimidines and thienopyrimidines. Eur. Chem. Bull., 4 (9) 436-441.

(17) Gad M. A., Aref S. A., Abdelhamid A. A., Elwassimy M. M., and Abdel-Raheem Sh. A. A. (2021) Biologically active organic compounds as insect growth regulators (IGRs): introduction, mode of action, and some synthetic methods. Curr. Chem. Lett., Accepted Manuscript (DOI: 10.5267/j.ccl.2021.005.004).

(18) Abdelhamid A. A., Elwassimy M. M., Aref S. A., and Gad M. A. (2019) Chemical design and bioefficacy screening of new insect growth regulators as potential insecticidal agents against Spodoptera littoralis (Boisd.). Biotechnology Reports, 24 (2019) 394-401.

(19) Su N. Y., and Scheffrahn R. H. (1990) Potential of insect growth regulators as termiticides: a review. Sociobiology, 17 (2) 313-328.

(20) Steelman C. D., Farlow J. E., Breaud T. P., and schilling P. E. (1975) Effects of insect growth regulators on psorophora columbiae (Dyar and $\mathrm{Knab}$ ) and non-target aquatic insect species in rice fields. Mosq. News, 35 (1) 67-76.

(21) Ganyard M. C., Bradley Jr J. R., Boyd F. J., and Brazzel J. R. (1977) Field evaluation of diflubenzuron (Dimilin) for control of boll weevil reproduction. J. Econ. Entomol., 70 (3) 347-350. 
(22) Bowers W. S., Ohta J. S., and Marsella P. A. (1979) Discovery of insect antijuvenile hormones in plants. Science, 193 (4253) 542-547.

(23) Brooks G. T. (1986) Insecticide metabolism and selective toxicity. Xenobiotica, 16 (10-11) 9891002.

(24) Medina P., Smagghe G., Budia F., Tirry L., and Vinuela E. (2003) Toxicity and absorption of azadirachtin, diflubenzuron, pyriproxyfen, and tebufenozide after topical application in predatory larvae of Chrysoperla carnea (Neuroptera: Chrysopidae). Environ. Entomol., 32 (1) 196-203.

(25) Mitsui T., Nobusawa C., and Fukami G. (1984) Mode of inhibition of chitin synthesis by diflubenzuron in the cabbage armyworm, Mamestrabrassicae L. J. Pestic. Sci., 9 (1) 19-26.

(26) Miura T., and Takahashi R. M. (1974) Insect development inhibitors; Effects of candidate mosquito control agents on non-target aquatic organism. Environ. Entomol., 3 (4) 631-636.

(27) Abdel-Aziz M., Abuo-Rahma G. A. A., Eman A. M., and Taha F. S. (2013) New nitric oxide donating 1,2,4-triazole/oxime hybrids: Synthesis, investigation of anti-inflammatory, ulceroginic liability and antiproliferative activities. Bioorg. Med. Chem., 21 (2013) 3839-3849.

(28) Alexander G. M., Denis V. K., Aleksey S. Y., and Oksana V. G. (2017) N-Substituted cyanacetohydrazides in the synthesis of 3,3-dialkyl-1,2,3,4-tetrahydroisoquinolines by Ritter reaction. Chem. Heterocycl. Compd., 53 (10) 1114-1119.

(29) Magdy M. H., and Abd El-Mawgoude H. K. (2016) Use of disubstituted thiosemicarbazide in synthesis of new derivatives of 1,3,4-thiadiazole, 1,2,4-triazole and pyrazole with their antimicrobial evaluation. J. Chem. Res., 6 (40) 345-350.

(30) Ishaaya I., and Horowitz A. R. (1992) Novel phenoxy juvenile hormone analog (pyriproxyfen) suppresses embryogenesis and adult emergence of sweetpotato whitefly (Homoptera: Aleyrodidae). J. Econ. Entomol., 85 (6) 2113-2117.

(31) Finny D. J. (1952) Probit Analysis: A Statistical Treatment of the Sigmoid Response Curve, 2nd Ed, Cambridge Univ. Press, Cambridge, U. K.

(32) Abbott W. S. (1925) A method of computing the effectiveness of an insecticide. J. Econ. Entomol., 18 (2) 265-267.

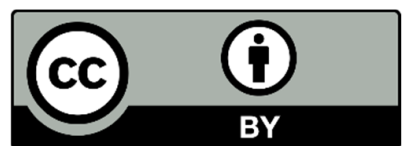

(C) 2021 by the authors; licensee Growing Science, Canada. This is an open access article distributed under the terms and conditions of the Creative Commons Attribution (CC-BY) license (http://creativecommons.org/licenses/by/4.0/). 